\title{
Original Article \\ Assessing the Learning environment of major Specialty PGRs in a tertiary care Hospital by Health Education Learning Environment Survey (HELES)
}

\author{
Qamar Ashfaq Ahmad ${ }^{1}$, Nafeesah Fatima², Muhammad Zeeshan Sarwar ${ }^{3}$ \\ 1 Professor, Department of Surgery, Services Institute of Medical Sciences Lahore. \\ 2 Assistant Professor, Services Hospital Lahore \\ 3 Assistant Professor, King Edward Medical University, Lahore
}

\section{ABSTRACT:}

Introduction: There are many surveys available to quantify -post-graduate residents' educational climate but they lack validity and theoretical background. Health education learning environment survey (HELES) is used in undergraduates with good results.

Objective: To quantify the current health education learning environment of our post-graduate residents of FCPS/MS/MD in Surgery, Medicine, and Gynae \& Obstetrics in a tertiary care hospital by using the HELES tool. This quantification will help Supervisors, Hospital administrators to monitor their programs, suggest, and bring improvement.

Methods: A cross-sectional study was done in Services Institute of Medical Sciences Lahore from $10^{\text {th }}$ Sep to $1^{\text {st }}$ Oct 2019. A sum of 90 residents in the FCPS/MS/MD program with 30 each from Surgery, Medicine, and Gynae \& Obstetrics were selected. Their response, graded through Likert scale, on a valid HELES proforma with 35 questions subdivided into 3 main dimensions \& 6 factors was used. In 'Personal development' dimension; work-life balance \& clinical skill development factors with a mean score of $34 \&$ above, in 'Relationship' dimension with Faculty and Peer relationship factors with a mean score of 48 \& above and in 'System maintenance' dimension with expectation \& educational setting factors a mean score of 48 \& above was taken as positive. Data were analyzed using SPSS 22 and a p-value of 0.05 was taken as significant.

Results: Out of 90 residents, 57 (63.3\%) were males and 33 (36.7\%) females. The mean age was $27.4 \pm 3.6$ years. The mean score of the residents in Surgery, Medicine, and Gynae \& Obs in all the 3 dimensions remained below the reference values, implying their dissatisfaction with the learning environment. Out of 6 factors, PGRs showed maximum dissatisfaction in the Faculty relationship $(88 \%)$ than in work-life balance (62\%) and clinical skill development \& expectations (61\%). In the System maintenance dimension, residents in Gynae \& Obs, with a mean score of 40.4, were having significantly low score as compared to Medicine, 46.2 and Surgery, 45.9. The comparison of means among different specialties was 0.02 , which was significant. Resident's response in all three dimensions with their year of training was significant with a p-value of $<0.05$. The $2^{\text {nd }}$ year residents of all 3 specialties scored high in all three dimensions.

Conclusion: Three major specialties; Medicine, Surgery, and Gynae \& Obs PGRs in a local tertiary care hospital, were dissatisfied with their health education learning environment as measured through HELES.

Keywords: Health, education, learning, environment, residents, HELES

doi: https://doi.org/10.53708/hpej.v3i1.101

This is an Open Access article and is licensed under a creative commons attribution (4.0 International License)

\section{INTRODUCTION}

In medical education, the learning environment can be considered as the educational, physical, social, and psychological context in which trainees are exposed and is believed to have a significant bearing on their professional and moral development (ColbertGetz, Kim, Goode, Shochet, \& Wright, 2014). Mohan et al. divided the educational climate into three main components; Physical climate (facilities, safety, food, and shelter), emotional climate (security and reinforcement), and intellectual climate (learning with patients, relevance to practice, evidence-based and up-to-date knowledge and skills) (Mohanna K, Wall D, 2004). The educational environment in any teaching institute is of utmost importance in fostering learning and acquisition of skills (S, 2010). This is a well-established fact that a supportive learning environment is essential for effective medical education (Colbert-getz et al., 2014).

\section{Correspondence:}

Dr. Qamar Ashfaq Ahmad

Email address: qamarsurg@yahoo.com,

Received: August 29, 2019 Accepted: October 5, 2019

Funding Source: Nil
There is a realization of the importance of the learning environment, not only at the undergraduate but also at the post-graduate level. Post-graduate studies, including FCPS and MS are very important in our post-graduate medical education system. These high stakes, level III, exit qualifications, require a robust educational system with up to the mark training and learning opportunities. Although these qualifications in a specific specialty have well-defined educational programs with predetermined competencies at the end of the training, these training slots are distributed in multiple units within the same institute or multiple institutes. So, the Post-graduate residents (PGR) can have a varied learning experience and their feedback regarding their health education program is an important but neglected area in our system.

Now the question arises, how to assess the learning environment of PGRs through a reliable tool to quantify it. To measure resident's perception of learning climate, in 1993 Seelig's residency program evaluation program tried to assess workload, faculty, and stress concerning the learning environment (Seel1C, 1993). In a study, the Dutch residency educational climate 
test D-RECT in Spanish was validated against the Spanish version of the post-graduate hospital educational environment measure( PHEEM) with good results (Dominguez LC, Silkens $M, 2019)$. Many surveys were developed but there is no gold standard for assessing student's or resident's perceptions about the learning environment (Colbert-getz et al., 2014). In recent reviews, objections were raised due to lack of Validity evidence and theoretical background (Johanna Scho"nrockAdema • Tineke Bouwkamp-Timmer, 2012), and in an attempt to improve these deficiencies, a newly developed 35-item Health Education Learning Environment Survey (HELES) was developed. It consists of six subscales: work-life balance, clinical skills development, faculty relationships, peer relationships, expectations, and educational setting (Rusticus, S. A., Wilson, D., Casiro, O., \& Lovato, 2019). There is no local published data available on HELES in our settings. This quantification tool was initially validated in undergraduates with encouraging results, and we plan to test it on post-graduate residents as well.

The current study is an attempt to quantify the learning environment at the level of PGRs in three major specialties; Medicine, Surgery, and Gynae \& Obs in a tertiary care hospital in Lahore. This quantification will help Supervisors, Hospital administrators, and even degree-awarding institutions to monitor their programs, suggest, and bring improvements.

\section{METHODS}

This cross-sectional study was conducted from $10^{\text {th }}$ Sep 2019 to $1^{\text {st }}$ Oct 2019 at the Services Institute of Medical Sciences (SIMS), Lahore. There are 4 units of General Surgery \& Medicine each and 3 units of Gynae \& Obstetrics. The training is supervised with designated supervisors in both FCPS, MS/MD.

A total of 90 residents of FCPS, MD/MS with 30 each in the Surgery, Medicine, and Gynae \& Obs departments, were recruited in the study using a convenient sampling technique. Both Male \& Female PGR's of FCPS \& MS Degree with a minimum of 6 months rotation in that specialty were included in the study. Incomplete responses were excluded from the study. Informed consent was taken and the identity of residents was masked to ensure anonymity. The hospital ethical committee approved the study.Data were collected on a predesigned "HELES Proforma" with a total of 35 items distributed in 3 dimensions with 6 subscales, representing student's overall perception of the learning environment.

The items were marked on a 5-point Likert scale. In each subscale, a positive item was marked for responses like 'strongly agree' (5) to 'strongly disagree' (1). For negative questions, the marking was strongly agreeing (1) to strongly disagree (5).

The first dimension was of 'Personal development' with two subscales of Work-life balance (7 items) and Clinical skill development (4 items) with a maximum of 38 and a minimum of 22 scores with a Mean of 34 , so a value equal or greater than this was considered as good/positive score. There were three negative questions in its $1^{\text {st }}$ subscale of Work-Life balance, which was marked accordingly (Table II).
The second dimension was the 'Relationship dimension' with two subscales of Faculty relationship (6 items) and Peer relationship (4 items) with a maximum score of 60 and a minimum score of 12, Mean score of 48 and greater was considered as good/positive score (Table III).

The third dimension was 'System maintenance' with two subscales Expectations (4 items) and Educational setting \& resource ( 6 items) with the maximum score of 60 and a minimum score of 12, Mean score of 48 and greater was considered as good/ positive score (Table IV).

Statistical analysis was be done by SPSS (version 22) and a series of item analyses (i.e., means, standard deviations, frequencies of options selected, item-item correlations) was done. The mean scores of residents from Surgery, Medicine, and Gynae \& obs were calculated and compared using ANOVA.

Results: Out of 90 residents, there were 33 (37\%) males and 57 (63\%) females. The mean age of the residents was $27.4 \pm 3.6$ years. There were 67 (74\%) FCPS and 23(26\%) MS/MD residents (Table I).

Table I Demographic Variables

\begin{tabular}{|c|c|}
\hline Variable & Frequency (\%) \\
\hline Male & $33(37 \%)$ \\
\hline Female & $57(63 \%)$ \\
\hline \multicolumn{2}{|c|}{ Degree Programme } \\
\hline FCPS & $23(74.2 \%)$ \\
\hline MD/MS & $30.8 \%)$ \\
\hline \multicolumn{2}{|c|}{ Specialty } \\
\hline Medicine & $30(32.3 \%)$ \\
\hline Surgery & $30(33.3 \%)$ \\
\hline Gynae \& Obs & $22(25 \%)$ \\
\hline \multicolumn{2}{|c|}{ Year of Residency } \\
\hline $2^{\text {st }}$ Year & $48(53 \%)$ \\
\hline $2^{\text {nd }}$ Year & $5(17 \%)$ \\
\hline $3^{\text {rd }}$ Year & $4^{\text {th }}$ Year \\
\hline
\end{tabular}

In the 'Personal development' dimension the mean score of residents from Surgery, Medicine, and Gynae \& Obs was 30.77, 29.67, and 29.70. These scores were less than the reference value of 34 , this showed a poor result of residents in the personal development dimension. The comparison of means of all specialties showed a p-value of 0.806 , which was statistically insignificant (Table II). 
Table II Score of specialty PGRs in 'Personal Development Dimension'

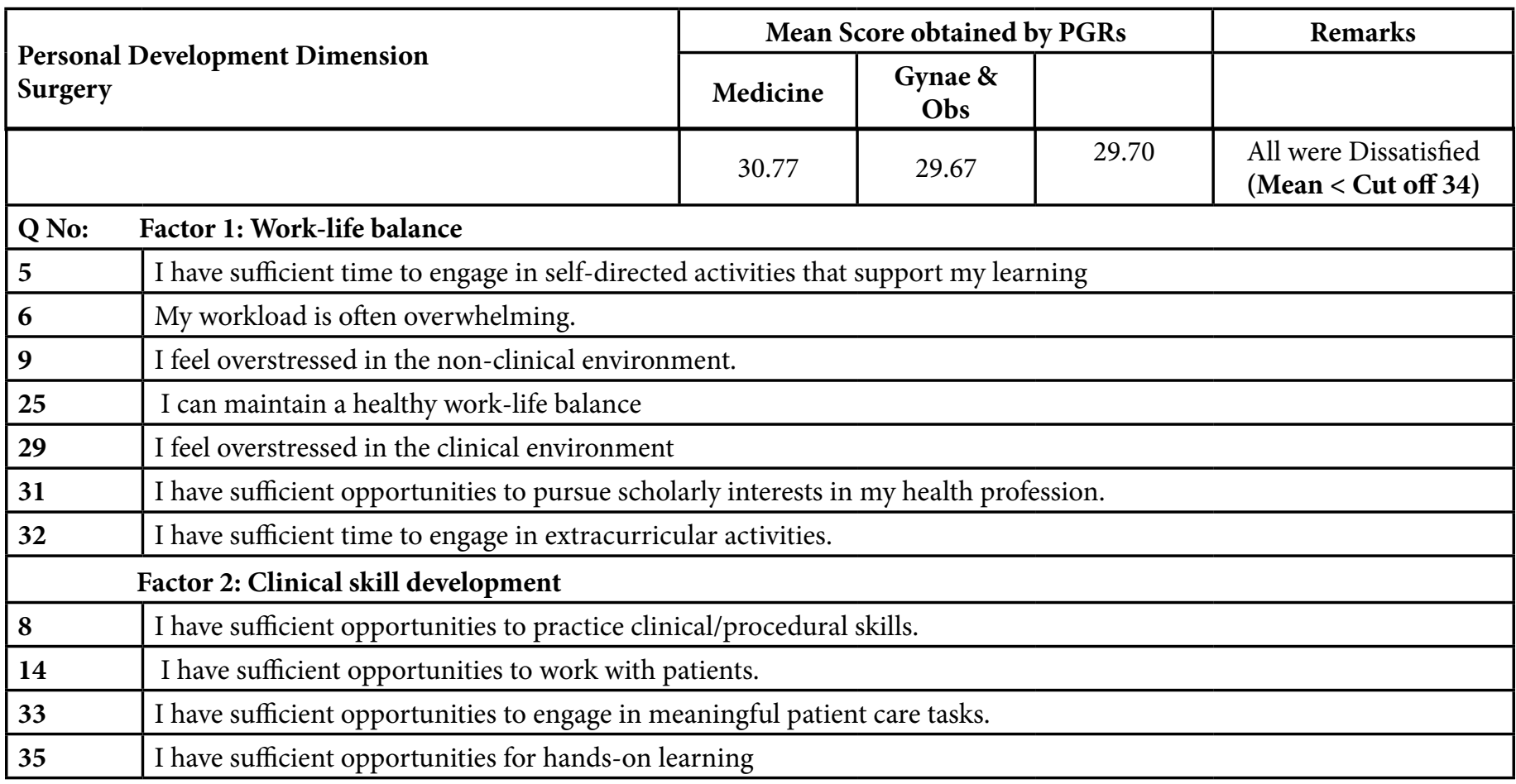

Table III Score of specialty PGRs in "Relationship Dimension"

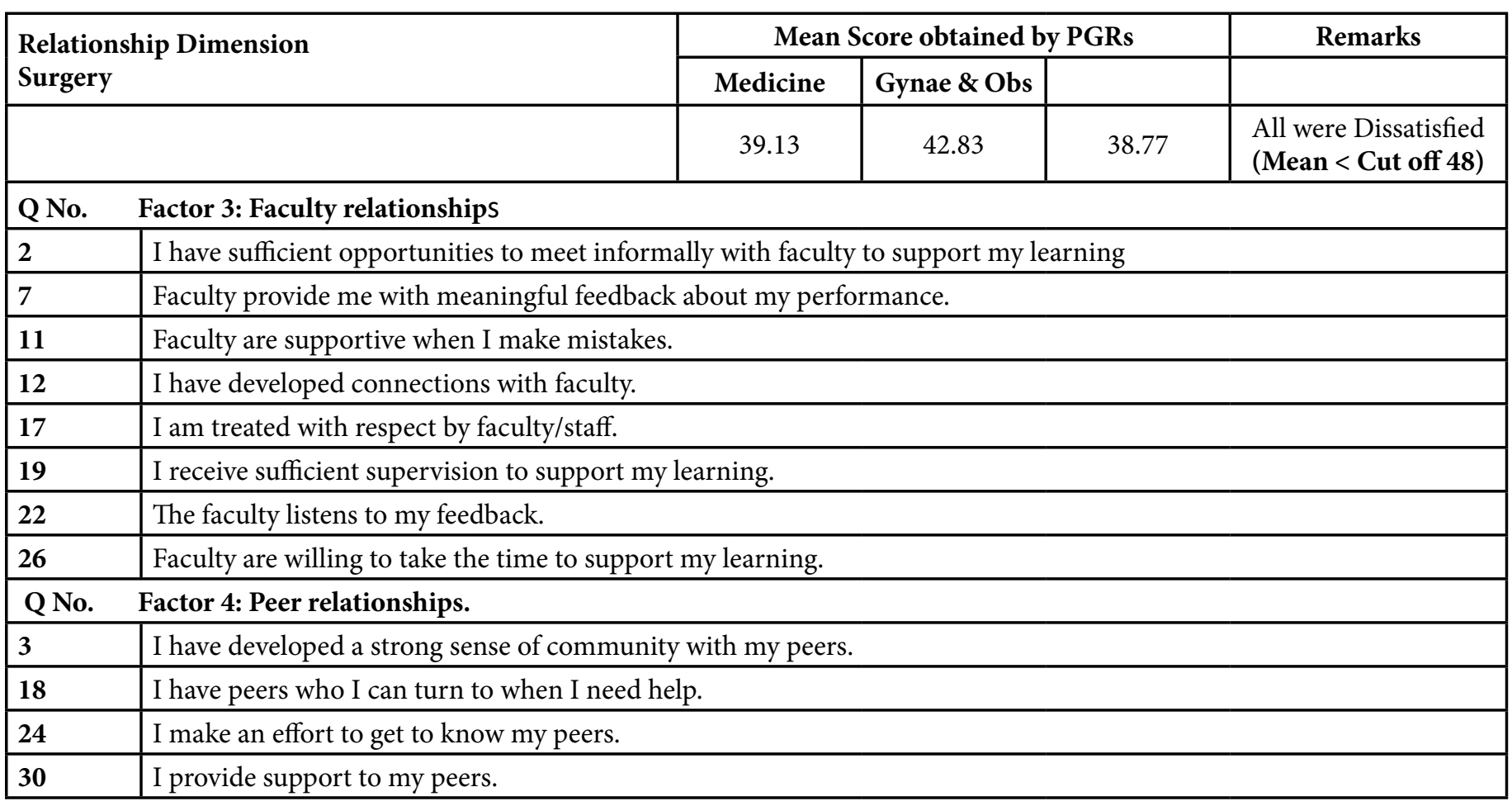

In the 'Relationship' dimension, the mean score of residents from Surgery, Medicine, and Gynae \& Obs was 39.13, 42.83, and 38.77 respectively. These scores were less than a reference value of 48. So, it reflected the poor performance of all specialties in this dimension too. The comparison among means showed a p-value of 0.157 , which was statistically insignificant (Table III).
Similarly, in the 'System maintenance' dimension, the mean score of Surgery, Medicine, and Gynae \& Obs residents was $45.90,46.27$, and 40.43 respectively. These values were again less than a reference value of 48 , which reflected the poor performance of all specialties in this dimension. However, the comparison among means of different specialties gave a p-value of 0.029 , which was statistically significant (Table IV). 
Table IV Score of specialty PGRs in 'System Maintenance Dimension'

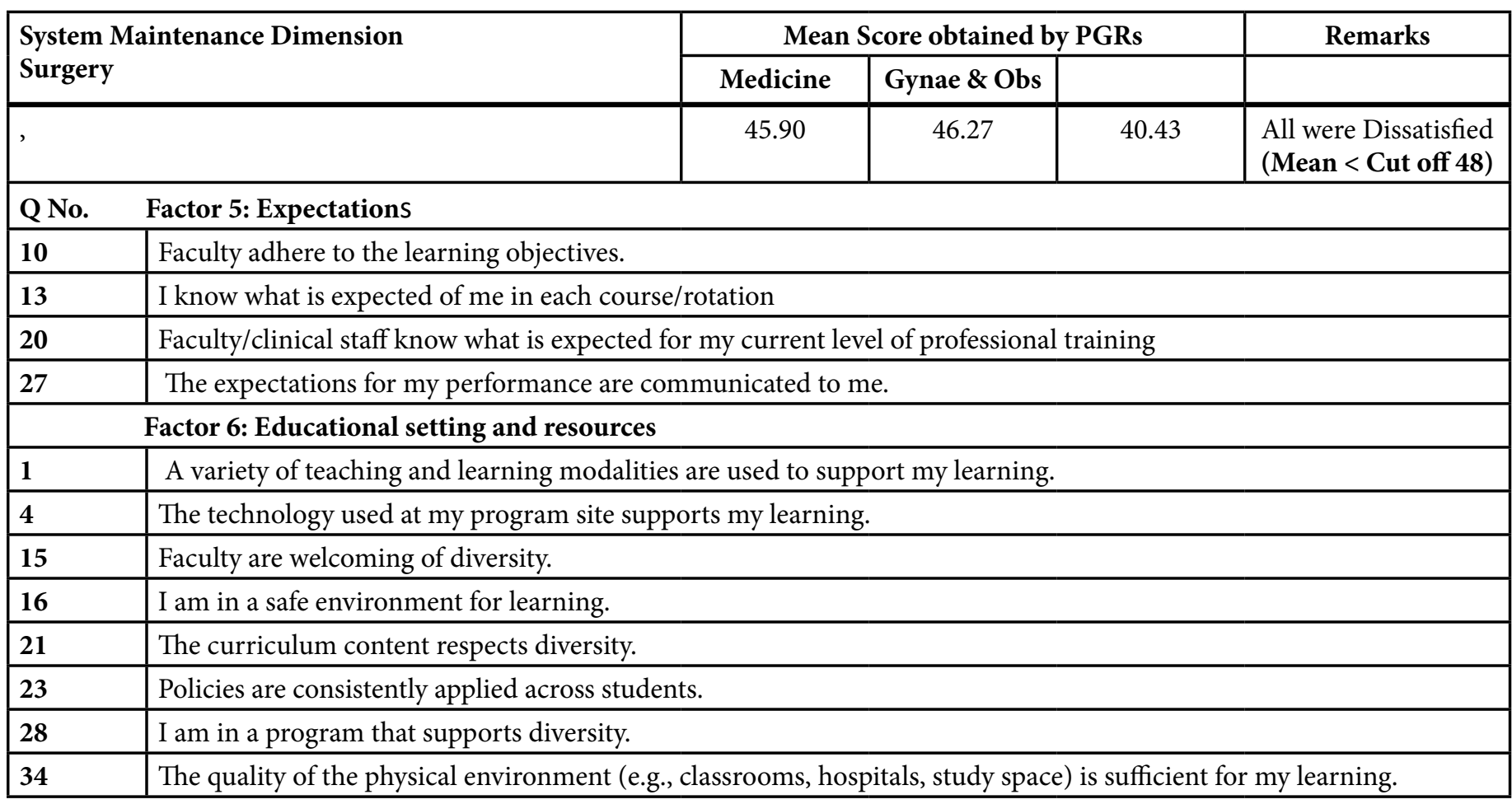

Table V Comparison of Residency status and their Mean score in different Dimensions.

\begin{tabular}{|c|c|c|c|c|c|c|}
\hline $\begin{array}{c}\text { Residency } \\
\text { status }\end{array}$ & $\begin{array}{c}\text { Personal } \\
\text { Development }\end{array}$ & p-Value & Relationship & p-Value & $\begin{array}{c}\text { System } \\
\text { Maintenance }\end{array}$ & p-value \\
\hline First year & $28.64 \pm 5.79$ & 0.024 & $38.36 \pm 7.43$ & 0.011 & $44.36 \pm 12.12$ & 0.039 \\
\hline Second-year & $32.21 \pm 6.50$ & & $43.02 \pm 8.88$ & & $46.44 \pm 8.36$ & $39.67 \pm 7.54$ \\
\hline Third-year & $27.33 \pm 9.88$ & & $34.87 \pm 10.22$ & & $37.25 \pm 3.68$ & \\
\hline Fourth-year & $25.00 \pm 4.24$ & & $39.50 \pm 1.73$ & & & \\
\hline
\end{tabular}

Table VI Individual Factors with overall responses.

\begin{tabular}{|l|l|c|c|c|}
\hline \multicolumn{1}{|c|}{ Dimension } & \multicolumn{1}{|c|}{ Factor } & Positive Response & Negative Response & Reference Value Score \\
\hline \multirow{2}{*}{ Personal Development } & 1: Work-Life Balance & $34(38 \%)$ & $56(62 \%)$ & $>22$ \\
\cline { 2 - 5 } & 2: Clinical Skills Development & $35(39 \%)$ & $55(61 \%)$ & $>12$ \\
\hline \multirow{2}{*}{ Relationship } & 3: Faculty Relationship & $21(22 \%)$ & $79(88 \%)$ & $>32$ \\
\cline { 2 - 5 } & 4: Peer Relationship & $38(42 \%)$ & $52(58 \%)$ & $>16$ \\
\hline \multirow{2}{*}{ System Maintenance } & 5: Expectations & $35(39 \%)$ & $55(61 \%)$ & $>16$ \\
\cline { 2 - 5 } & $\begin{array}{l}\text { 6: Educational Setting \& } \\
\text { Resources }\end{array}$ & $37(41 \%)$ & $53(59 \%)$ & $>32$ \\
\hline
\end{tabular}

There was no significant difference between gender and the resident's response.

\section{DISCUSSION}

Health education learning environment has a significant impact on pupils' development and growth. A positive educational environment must be created to motivate student's learning (Kirkpatrick, 1996). Many instruments have been developed, keeping in mind various theories of educational psychologists. Sociocultural theory, in particular, is considered a promising theory explaining how learning occurs in a dynamic atmosphere like a clinical educational environment (Bleakley, 2006). Interaction with others like; peer relationships and faculty relationships are a good example of sociocultural learning. Health Education Learning Environment Survey (HELES) is one of the recently developed instruments to quantify the educational 
learning environment. This was based on 'Moos' theoretical background, which is widely accepted and it emphasizes the value of the human environment, irrespective of the type of setting, and can be described by three main dimensions (Moos, 1973). The Integrated system approach was taken as a theoretical framework for the assessment of the medical school learning environment and formed the basis of the development of HELES (Rusticus, S. A., Wilson, D., Casiro, O., \& Lovato, 2019).

The importance of these three dimensions can be exemplified by their subscales and their inherent content. The first dimension is 'Personal Development', which is an educational environment, refers to attaining one's aims of education. So, an educational environment that is high in Personal Development means clarity of Learning objectives, relevant learning content, and construction. The second dimension points towards Relationship, which identifies the extent to which residents are involved in setting, support, aiding each other, and expressing themselves spontaneously, openly, and freely. A favorable second dimension, 'Relationship' refers to an educational environment with cohesion, open communication, friendliness, social support, and group spirit. A positive relationship refers to student involvement, affiliation, teacher support, and emotional stability.

The third dimension, 'System Maintenance' measures the extent to which the environment is orderly and clear in its expectations. In educational settings, examples include order, organization, rule clarity, teacher control, student influence, and innovation (Johanna Scho"nrock-Adema. Tineke Bouwkamp-Timmer, 2012). In the current study, on a sample of 90 residents, all the residents' mean score in all the dimensions was below average, which implies that our post-graduates are not content with the learning environment they live in. This finding has strong implications for their professional and personal development (Table II, III, IV). Post-graduate students are the future consultants who are expected to go through robust training to evolve into experts in their fields. This can only be accomplished once they are raised and educated in a congenial and friendly environment.

If we look at the overall trend of the level of satisfaction in the three specialties, in the 'Relationship' dimension $81 \%(n=73)$ of residents were discontent, meaning they consider their learning environment as demoralizing, less friendly with little social support. Once we explore further, it is evident that a maximum of $88 \%(n=79)$ of residents were dissatisfied with the 'faculty relationship' factor. This shows that residents feel detached from their teachers and there could be multiple reasons, like lack of time, interest, and willingness on the part of faculty. (Table VI)

In the same way, $73 \%(\mathrm{n}=66)$ were dissatisfied with the System maintenance domain, exhibiting that they feel their learning environment is disorderly, having less teacher control and role clarity. In this domain maximum of $61 \%(n=55)$ were unhappy with the 'Expectations' factor, especially from faculty. In the Personal development domain, 69\% $(n=62)$ were dissatisfied and we're feeling low in goal direction, having problems with learning content and clarity. Out of these maxima of $62 \%(n=56)$ had a negative response in the 'Work-Life Balance' factor, showing an apprehension of increased workload and work- related anxiety (Table VI) Moreover, in our study, we found out some important differences between Surgery, Medicine, and Gynae \& Obs residents in the 'System maintenance' dimension ( $\mathrm{p}$-value $=0.029$ ). System maintenance encompasses expectations, educational setting, and resources. It seems that residents in Gynae \& Obs, with a mean score of 40.4, were having significantly low scores as compared to residents in Medicine 46.2 and Surgery 45.9. So, the department of Gynae \& Obs should make extra effort to improve its learning environment in this domain (Table IV). However, no significant difference was found in the three specialties in terms of personal development and relationship dimensions. All three specialties uniformly scored low on personal development and relationship dimensions explaining that no specialty is any better than the other. These results throw light on some important aspects such as there is a lack of harmony among residents at their workplace. There is a general tendency of not helping others and make things easy for each other. Moreover, our residents think their environment does not have the potential for personal growth and self-development.

Once we compare it with PHEEM (Postgraduate hospital educational environment measure), few questions asked in the Social support dimension are similar to Relationship and System maintenance domains in the HELES study. The perception of the learning domain in PHEEM is somewhat similar to the Relationship (with Faculty) dimension. So the findings of the current study are in line with PHEEM were negative responses in, 'Perception of Teaching' which showed that teaching and training didn't meet the majority of trainees' expectations (S, 2010). A few years back, a PHEEM study done in Services hospital, Lahore concluded that the educational environment was satisfactory with a lot of room for improvement (Sandhu et al., 2018). These findings are different from a current study, which gives a deeper insight into a current learning environment.

Once we compare resident's responses in all three dimensions with their year of training, it turned out to be significant with a p-value of $<0.05$. Second-year residents of all specialties scored comparatively high in all three dimensions. This could be explained by the fact that residents become more responsible, familiar with working conditions, and develop a positive relationship with their teachers and peers and feel at ease as they become seniors. (Table V). These findings give us an idea that the supervisors, hospital administrators, and college/university authorities must take immediate steps to improve the learning environment in all specialties by making their environment more supportive, friendly, orderly \& organized, goal-oriented, and objectively structured.

\section{CONCLUSION}

Three major specialties; Medicine, Surgery, and Gynae \& Obs PGRs in a local tertiary care hospital were dissatisfied with their health education learning environment as measured through HELES. Maximum residents were discontent in Faculty relationship factors, then in work-life balance and clinical skill development factors.

Impact of study: This study identifies relevant factors within three main dimensions, in which the majority of our educational learning environment is deficient. 
We will share our findings with relevant stakeholders, including supervisors, and suggest measures to improve the situation. Identification should lead to the rectification of problems.

\section{Limitations}

This was a cross-sectional survey with a small sample size of 30 each in the three main specialties. The sample size could be increased with more specialties to get a better representation of the resident's perspective. We could not collect an equal sample from all 4 units from a major specialty, so unit wise learning environment could not be assessed properly.

\section{Way Forward}

HELES is a theoretically valid and robust tool that can easily be employed in our tertiary care hospital settings. We can use it regularly to gather data and implement corrective strategies to improve the learning environment.

\section{DECLARATION OF INTEREST:}

Authors report no declaration of interest

\section{REFERENCES}

Bleakley, A. (2006). Broadening conceptions of learning in medical education: The message from teamworking. Medical Education, 40, 150-157.

C, S. (1993). Quantitating qualitative issues in residency training: development and testing of a scaled program evaluation questionnaire. Journal of General Internal Medicine, 8(11), 610-613.

Colbert-Getz, J. M., Kim, S., Goode, V. H., Shochet, R. B, \& Wright, S. M. J. A. M. (2014). Assessing medical students' and residents' perceptions of the learning environment: exploring validity evidence for the interpretation of scores from existing tools. 89(12), 1687-1693.

Committee on Accreditation of Canadian Medical Schools. (2016). (n.d).

Dominguez LC, Silkens M, S. A. (2019). The Dutch residency educational climate test: construct and concurrent validation in the Spanish language. International Journal of Medical Education, 10, 138-148.

Johanna Scho"nrock-Adema,Tineke Bouwkamp-Timmer. (2012). Key elements in assessing the educational environment: where is the theory? Adv in Health Sci Educ, 17, 727-742.
Kirkpatrick, D. L. (1996). Great ideas revisited: Techniques for evaluating training programs. Revisiting Kirkpatrick's four-level model. Training and Development, 50, 54-59.

Mohanna K, Wall D, C. R. (2004). Teaching made easy: a manual for health professionals. Educational Concepts: the theory behind the practical aspects of teaching and learning (2nd ed.). Retrieved from-https://www.uc.pt/fmuc/gabineteeducacaomedica/ recursoseducare/livro41

Moos, R. H. (1973). Conceptualizations of human environments. American Psychologist, 28, 652-655.

Rusticus, S. A., Wilson, D., Casiro, O., \& Lovato, C. (2019). Evaluating the Quality of Health Professions Learning Environments: Development and Validation of the Health Education Learning Environment Survey (HELES). Evaluation \& the Health Professions. Retrieved from https://doi. org/10.1177/0163278719834339.

S, A. (2010). Assessment of educational environment for interns using Postgraduate Hospital Educational Environment Measure (PHEEM). Journal of Taibah University Medical Sciences, 5(1), $1-12$.

Sandhu, A., Liaqat, N., Waheed, K., Ejaz, S., Khanum, A., Butt, A, Dar, s. h. j. j. p. m. a. (2018). Evaluation of the educational environment for post-graduate residents using post-graduate hospital educational environment measure. 68(5), 790-792.

Seel1C, C. B. (1993). Quantitating qualitative issues in residency training. Journal of General Internal Medicine, 8(11), 610-613. doi:10.1007/BF02599716

Standards for accreditation of Medical \& Dental colleges. (n.d.). Retrieved from file://C:/Users/HP/Desktop/PMDC/PMDC Evaluation Visit/9- Standards of Accreditation of medical and dental colleges along with self-assessment porforma.pdf

\section{AUTHORS CONTRIBUTION}

1. Qamar Ashfaq Ahmad: Analysis and interpretation of data.

2. Nafeesah Fatima: Critical review and final approval of the version to be published

3. Muhammad Zeeshan Sarwar: Analysis and interpretation of data. 